\title{
A profile of patients attending sports medicine clinics
}

C F Finch, M A R Kenihan

\begin{abstract}
Objectives-To describe the sociodemographic profile of sports injury patients who attend sports medicine clinics for treatment and to describe their reasons for choosing to attend such clinics.

Method-Data were collected as part of a fully audited injury surveillance system implemented within sports medicine clinics. The study was conducted within five allied multidisciplinary sports medicine clinics in metropolitan Melbourne, Australia. All patients initially presenting for treatment of a new sports or active recreation injury over the period August 1997 to August 1998 were eligible for this study, irrespective of the practitioner providing the treatment. Data were obtained on 6476 patients.
\end{abstract}

Results-The median age of the patients was 25.4 years (range $6.8-81.6$ ) and most were male $(69.8 \%$ of cases; $95 \%$ confidence interval (95\% CI) 68.7 to 70.9$)$. Patients had both professional and nonprofessional backgrounds and were not just local suburb residents. Many patients had insurance cover for their injury treatment: $59.0 \%$ (95\% CI 58.6 to 59.4$)$ had some private health insurance and $46.6 \%$ (95\% CI 45.4 to 47.8$)$ had club/association insurance. The most common reasons for attending a clinic was its location $\mathbf{( 3 6 . 8 \%}$; $95 \%$ CI 36.5 to 37.1 ) and referral/ recommendation $(31.0 \%$; $95 \%$ CI 30.7 to 31.3).

Conclusion-Sports medicine clinics provide treatment for a broad spectrum of injured sports participants across a variety of sporting/recreation contexts. Although these clinics mainly serve the immediate geographic community, the sports speciality and expertise of a particular clinic can attract patients from further afield. This information can help sports medicine clinics to market their services more efficiently to meet the needs of their potential patients.

(Br f Sports Med 2001;35:251-256)

Keywords: clinics; injuries

Sports injuries are a significant public health issue in Australia. ${ }^{1-3}$ It has been estimated that one in 17 Australians experience a sports injury each year, costing 1 billion dollars per annum. ${ }^{1}$ Accordingly, the prevention of sports injuries has been identified as a priority National
Health Goal and Target for Injury Prevention and Control. ${ }^{24}$

Despite this public health priority ranking, data on sports injuries in Australia are limited, with no regular standardised collections of data in general use. ${ }^{3}$ The main sources of routinely collected population based injury data are hospital admission, emergency department, and coronial records. ${ }^{5}$ However, these sources only have the potential to access fewer than $30 \%$ of all sports injuries as they only represent the most serious cases, which have resulted in death or hospital admission. ${ }^{6}$

Another limitation of hospital based sports injury data is that patients attending hospitals for treatment of a sports injury commonly suffer from acute injuries, often affecting the upper extremity or head. ${ }^{58}$ Many sports injuries are chronic or overuse in nature and are consequently unlikely to be treated in hospital. Some Australian studies have found that patients seeking treatment for their sports injury at a sports medicine clinic or general practice are likely to have sustained a less severe injury such as a sprain or bruise in the lower limb region. ${ }^{6} 910$

Increased community participation in sport and active recreational pursuits, as well as the increasing media reporting of sports injury care for elite athletes, has prompted the establishment of sports medicine clinics throughout Australia to provide multidisciplinary care for injured athletes. ${ }^{9}$ Treatment at a sports medicine clinic often has a better outcome because a range of practitioners can be jointly involved at the same time and location.

Information about injuries treated at sports medicine clinics has the potential to provide valuable data on sports injuries by providing a greater representation of the sports injury problem, across the full spectrum of injury severity. ${ }^{67-12}$ To date, there has only been one published study describing cases treated at a sports medicine clinic in Australia. ${ }^{9}$ This and similar international studies have typically described patients of sports medicine clinics according to injury type, injury site, and the sport associated with the injury. ${ }^{9}{ }^{13} 14$ These studies have not provided a full profile of the patients choosing to attend such a clinic. This information is necessary for sports medicine clinics to market their services more effectively to meet the needs of their potential patients.

In Australia, services provided by sports physicians are covered by the universal health scheme Medicare. Medicare is operated federally by the Health Insurance Commission which sets rebates for the services that the health scheme covers and is funded by a tax 
payer levy. Fees charged in excess of the rebate are paid by the patient. Medicare does not cover non-medical fees such as physiotherapy costs. Private health insurance companies cover a range of paramedical services such as physiotherapy and podiatry, as well as private hospital stays. Users pay annual fees to have such insurance coverage. These companies offer a variety of products, the benefit of which is determined by the amount the user pays.

The aim of this study was to profile the patients who attended one of five sports medicine clinics in Melbourne over one year and to describe their reasons for attending.

\section{Methods}

The Sports Medicine Injury Surveillance (SMIS) project was established to provide a comprehensive description of sports injuries presenting to sports medicine clinics for treatment of a new sports injury. The SMIS project was implemented in five allied sports medicine clinics in metropolitan Melbourne over one year. The Sports Medicine Centres of Victoria (SMCV) group was selected for this project because of its geographic coverage across the Melbourne metropolitan area and the fact that there was a common management structure across all five clinics. The SMCV group was established in 1980 and has significant numbers of patient attendances; it provides a broad spectrum of sports medicine care from sports physicians, physiotherapists, podiatrists, masseurs, and nutritionists.

Data collection began on 12 August 1996 and continued until 11 August 1997. All sport and active recreation injury cases presenting to one of the participating sports medicine clinics for initial treatment of an injury during the data collection period were eligible for this study. Patients were invited to participate in the study by reception staff and given a plain language statement, informed consent form, and an injury surveillance form to complete while waiting for their practitioner. There were no restrictions on patient eligibility in terms of age, sex, injury type, type of sport activity, injury severity, or type of practitioner being consulted.

A two sided injury surveillance form was designed to gather the information. The first side was completed by the person presenting for treatment, or their guardian, and requested personal details and information on sports participation, injury occurrence, health insurance cover, and reasons for attending the clinic. Generally, closed questions were used, with some open ended questions to elicit other responses not specifically specified. Patients were asked to choose from a number of specified responses describing their reasons for choosing to attend the clinic: referral, location, advertisement, cost, reputation, previous patient, range of professionals, sports speciality, club/association connection with centre, and other (specify). More than one response could be given. Patients were also asked to state if they had hospital insurance cover only, extras (non-medical services) insurance cover only, both hospital and extras insurance cover, no health insurance cover, or unsure. Patients were also asked to indicate who had referred them to the clinic for treatment: self, friend, local doctor, club physiotherapist/doctor, and other (specify).

The second side was completed by the attending practitioner and recorded the provisional injury diagnosis, treatment given, and initial assessment of injury severity. Once patients had completed their side of the form, they handed it to their sports medicine practitioner who completed the remaining section of the form.

Ethics approval was obtained from both the Deakin University ethics committee and the Monash University standing committee on ethics in research on humans. All patients provided written informed consent to participate in this study.

Over the 12 month data collection period, 6911 new sports injury cases were treated at one of the five sports medicine clinics. The injury surveillance system captured data on 6476 sports injury patients (or $93.7 \%$ of the total). It was not possible to determine whether the non-responders had been "missed" by the injury surveillance capture process or whether they refused to participate in the study. A database was established from the completed injury surveillance forms. Data describing the profile of patients attending one of these sports medicine clinics was extracted from this database. As these data are descriptive, a descriptive statistical analysis was performed and $95 \%$ confidence intervals $(95 \% \mathrm{CI})$ for results given as appropriate.

As the SMIS project was not conducted within a well defined region, injury rates (per head of population) could not be computed. To assess whether the cases in the SMIS project were representative of the wider Victorian population and general sports participants, the age and sex distributions were compared with published Australian Bureau of Statistics (ABS) figures. ${ }^{15}$ Because only summary age distribution data were obtainable from the ABS reports, the SMIS data were regrouped into the ABS age categories for these comparisons. Not everybody participates in sporting pursuits, and it is possible that any differences between the SMIS project data and the general population could reflect the age and sex distributions of participants as opposed to the wider population. The age and sex distributions of the SMIS project cases were therefore also compared with ABS data for sports and physical activity participants in Victoria. ${ }^{16}$ As ABS participation data were only collected for persons aged at least 18 years and the published data were given for specific age groups, the age distribution for people aged 18 years and over in the SMIS project was grouped into the published ABS age categories. A $\chi^{2}$ test was used to compare the distributions of the SMIS project cases and the ABS published figures.

\section{Results}

SOCIODEMOGRAPHIC PROFILE

Figure 1 shows the age distribution of the patients at the time of initial presentation at 


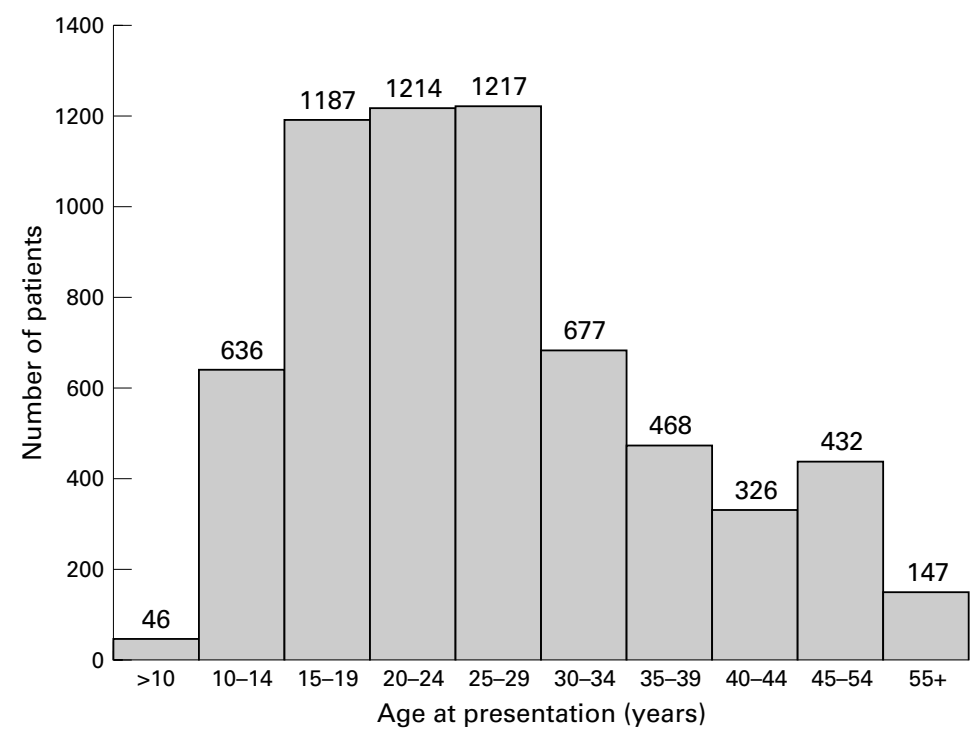

Figure 1 Age distribution of patients presenting at sports medicine clinics $(n=6476)$.

one of the sports medicine clinics. The median age of patients was 25.4 years (range 6.8-81.6). Over half $(57.0 \%)$ of the patients were aged between 15 and 30 years. Only $10.7 \%$ were aged under 15 years, and $2.3 \%$ were aged more than 55 years.

Table 1 compares the SMIS project age distribution with that of the general Victorian population. Although the modal age category for both was 20-59 years, there was a greater proportion of SMIS project cases in this group than the general Victorian population $(74.7 \%$ v $56.0 \%$ respectively). Only $1.1 \%$ of patients in the SMIS project were aged 60 years or over compared with $16.5 \%$ of the general Victorian population. Accordingly, there was a significant difference between the age distribution of SMIS project cases and the general Victorian population $\left(\chi_{4}^{2}=1078.2, \mathrm{p}<0.001\right)$.

Table 1 also shows that the SMIS project cases were also younger, on the whole, than general sports participants in Victoria. The SMIS project age distribution was closer to that of ABS sports participants (aged at least 18 years), although there was still an overall significant difference $\left(\chi_{4}^{2}=1340.4, \mathrm{p}<0.001\right)$.

A significantly higher proportion of the cases treated at the SMIS project clinics were in men $(69.8 \% ; 95 \%$ CI 68.7 to 70.9$)$ than in women $(30.2 \% ; 95 \%$ CI 29.1 to 31.3$)(\mathrm{p}<0.001)$. These proportions were significantly different from the gender distribution of both the general Victorian population $\left(\chi_{1}^{2}=1078.2\right.$, $\mathrm{p}<0.001)$ and sports participants $\left(\chi_{1}^{2}=628.3\right.$, $\mathrm{p}<0.001$ ) (table 1).

The occupations of the patients were categorised according to ABS categories with an additional category representing students. ${ }^{17} \mathrm{~A}$ large proportion of SMIS project patients were students (33.8\%; 95\% CI 33.5 to 34.1$)$. Other common occupational categories were professionals $(21.7 \% ; 95 \%$ CI 21.4 to 22.0$)$, tradespersons $(11.9 \% ; 95 \%$ CI 11.7 to 12.1$)$, and managers/administrators $(10.0 \%$; 95\% CI 9.8 to 10.2). These occupational categories are also common among the general Victorian population, according to the ABS Labour Force study, which did not consider students. ${ }^{17}$ According to this ABS survey in 1997, ${ }^{17} 19.6 \%$ of the general population were professionals and $14.1 \%$ were tradespersons.

Not surprisingly, given the location of the clinics, most $(88.4 \% ; 95 \%$ CI 87.8 to 88.9$)$ of the patients resided in a broad cross section of metropolitan Melbourne (inner city, eastern, southern, western, and outer southeastern suburbs) (fig 2). However, some sports injury patients who usually resided in regional or rural Victoria also attended the SMIS project clinics $(11.0 \%$; $95 \%$ CI 10.8 to 11.2$)$. In addition, a small proportion of patients attending the sports medicine clinics for treatment usually resided interstate $(0.6 \% ; 95 \%$ CI 0.6 to $0.7)$.

INSURANCE PROFILE

As the participating clinics were all private, patients attending one of them were usually required to pay for their treatment unless they had some form of insurance cover. Patients were eligible for a Medicare rebate for some of the costs. Those with extras insurance coverage were eligible to obtain a rebate for their ancillary health service charges. Figure 3 shows that just over half of all patients $(59.0 \% ; 95 \%$ CI 58.6 to 59.4) had some form of private health insurance (hospital and/or extras) to help cover the costs of treatment. In total, $39.6 \%$ had private hospital cover and $33.7 \%$ extras cover. This is significantly higher $(\mathrm{Z}=$ $14.2, \mathrm{p}<0.001$ ) than the $31.4 \%$ of Australians in the general population reported to have hospital cover during the same year. ${ }^{18}$

Almost half $(46.6 \%)$ of all SMIS project cases had sporting club or association insurance. This reflects the fact that over half $(54.8 \%)$ of the patients were injured during

Table 1 Age and sex distribution of patients attending sports medicine clinics for treatment, compared with the Victorian general population ${ }^{15}$ and the Victorian sports participant population ${ }^{16}$

\begin{tabular}{|c|c|c|c|c|c|c|c|}
\hline & & $\begin{array}{l}\% \text { of } \\
\text { SMIS cases }\end{array}$ & $\begin{array}{l}\text { Victorian } \\
\text { population }\end{array}$ & & & $\begin{array}{l}\% \text { of SMIS } \\
\text { cases (aged } \\
\geqslant 18 \text { years)* }\end{array}$ & $\begin{array}{l}\text { Victorian } \\
\text { sports } \\
\text { participants * }\end{array}$ \\
\hline \multirow{5}{*}{ Age group $\dagger$} & $<15$ & 10.7 & 20.6 & \multirow{5}{*}{ Age group $\dagger$} & $18-24$ & 30.9 & 20.3 \\
\hline & $15-19$ & 18.7 & 6.9 & & $25-34$ & 40.1 & 27.2 \\
\hline & $20-59$ & 69.5 & 56.0 & & $35-44$ & 16.4 & 21.9 \\
\hline & $60-64$ & 0.7 & 4.0 & & $45-54$ & 9.2 & 15.7 \\
\hline & $>65$ & 0.4 & 12.5 & & $55+$ & 3.4 & 14.9 \\
\hline \multirow[t]{2}{*}{ Sex $(\%)$} & Male & 69.8 & 49.4 & \multirow[t]{2}{*}{ Sex $(\%)$} & Male & 72.1 & 54.3 \\
\hline & Female & 30.2 & 50.6 & & Female & 27.9 & 45.7 \\
\hline
\end{tabular}

*As ABS participation data are for adults only, this comparison includes only participants/patients aged 18 years and over. tThese age groups are those given in the ABS publications.

SMIS, Sports Medicine Injury Surveillance project. 
The Sports Medicine Injury Surveillance (SMIS) Project.

Number of new sports injury presentations treated at each clinic by postcode of residence, $12 \backslash 8 \backslash 1996-11 \backslash 8 \backslash 1997$

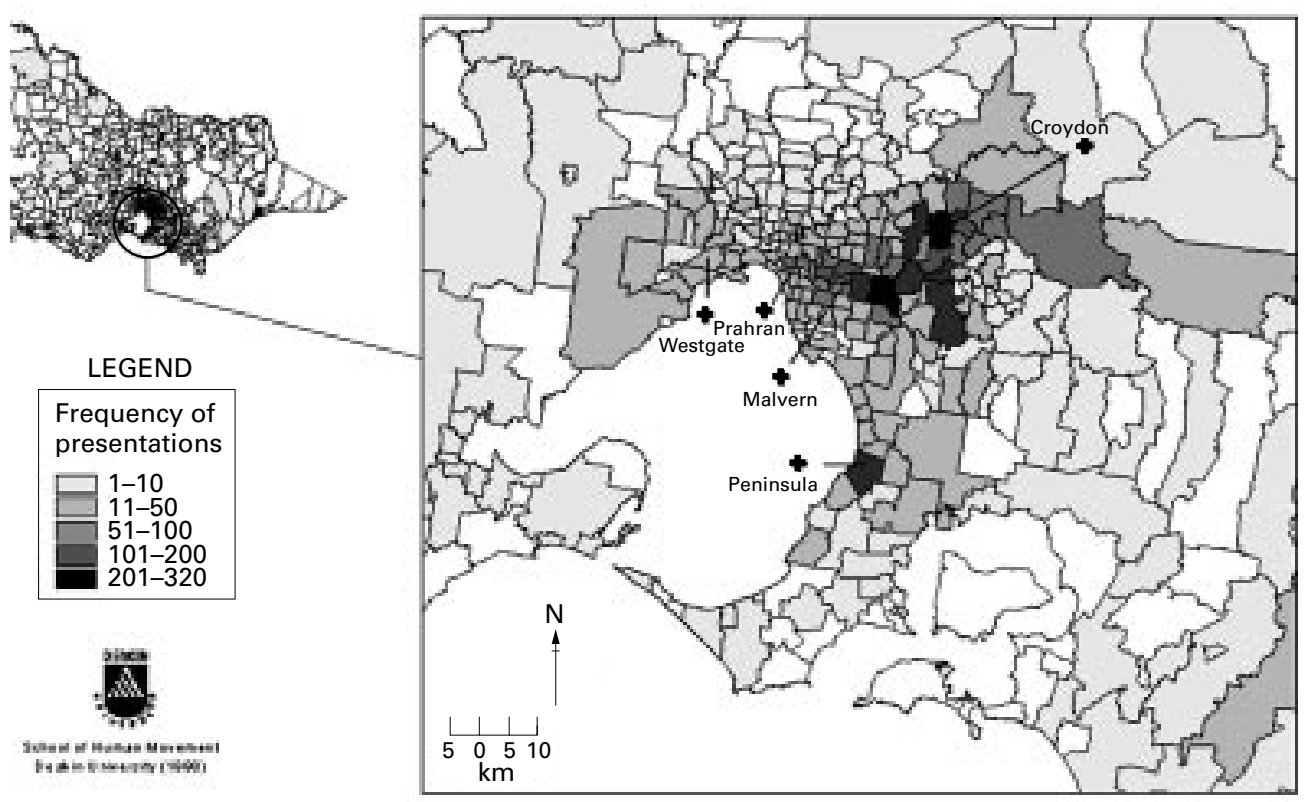

Figure 2 Geographic distribution of the postcode of usual residence of new sports injury patients presenting at sports medicine clinics.

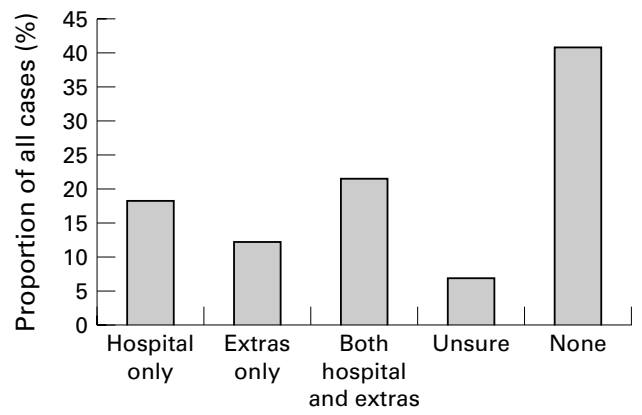

Type of health insurance cover

Figure 3 Proportion of sports injury cases treated at sports medicine clinics with private health insurance.

formal sporting competition and many of these participants would be registered sports participants and therefore covered by such an insurance scheme. In contrast, $15.0 \%$ of patients were injured during recreation activities and $10.7 \%$ during self training. Of the patients with club/association insurance, $44.5 \%$ were not concurrently covered by private health insurance, compared with the $54.8 \%$ of participants without club/association insurance who had some form of private health cover.

REASONS FOR ATTENDING A SPORTS MEDICINE CLINIC

A substantial proportion of patients referred themselves to the SMIS project clinics (table 2). Many patients attended at the recommendation of friends or were referred to the clinic by their club trainers or their own doctor/ physiotherapist.

Table 3 shows that the most commonly cited reasons for choosing to attend one of these sports medicine clinics were the location, a
Table 2 Source of referral of patients presenting to sports medicine clinics $(n=6476)$

\begin{tabular}{lrc}
\hline Source & \multicolumn{1}{l}{$n$} & $\%(95 \%$ CI $)$ \\
\hline Self & 2676 & $41.3(40.9$ to 41.7$)$ \\
Friend & 1307 & $20.2(19.9$ to 20.5$)$ \\
Club trainer & 919 & $14.2(14.0$ to 14.4$)$ \\
Own doctor & 387 & $6.0(5.9$ to 6.1$)$ \\
Family/relatives & 345 & $5.3(5.2$ to 5.4$)$ \\
Own physiotherapist & 336 & $5.2(5.1$ to 5.3$)$ \\
Sporting club/association/venue & 252 & $3.9(3.8$ to 4.0$)$ \\
Other medical setting/specialist & 160 & $2.5(2.4$ to 2.6$)$ \\
\hline
\end{tabular}

Table 3 Most commonly cited reasons for attending one of the sports medicine clinics for treatment of a sports injury

\begin{tabular}{lrc}
\hline Reason for attending clinic & $n$ & $\%(95 \%$ CI) \\
\hline $\begin{array}{l}\text { Location } \\
\text { Referral/recommendation }\end{array}$ & 2338 & $36.8(36.5$ to 37.1$)$ \\
$\begin{array}{l}\text { Sports speciality of clinic } \\
\text { Previous patient at clinic }\end{array}$ & 1788 & $31.0(30.7$ to 31.3$)$ \\
$\begin{array}{l}\text { Reputation of clinic/sports } \\
\quad \text { medicine professional }\end{array}$ & 1731 & $27.4(27.8$ to 28.4$)$ \\
$\begin{array}{l}\text { Sporting club/association } \\
\quad \text { connection with clinic }\end{array}$ & 1397 & $22.0(21.7$ to 22.3$)$ \\
$\begin{array}{l}\text { The range of professionals } \\
\text { Advertisement }\end{array}$ & 768 & $12.1(11.9$ to 12.3$)$ \\
Cost & 498 & $7.8(7.6$ to 8.0$)$ \\
\hline
\end{tabular}

More than one response could be given.

referral or recommendation, and the sports speciality of the clinic. The reason in over $25 \%$ of cases was previous attendance at the clinic, and the clinic's reputation was also an influential factor.

\section{Discussion}

This study is the first large scale, fully audited, multiclinic, injury surveillance project to describe attendance at sports medicine clinics in Australia. The findings show that the backgrounds of people attending sports medicine clinics and their reasons for doing so are varied. 
In general, patients attending a sports medicine clinic are younger than both the general population and community based sports participants. This could be because younger people tend to participate in collision and contact sports, which have a high risk of injury. Also, younger people may choose to attend a sports medicine clinic when injured because of a perceived greater emphasis on health issues relating to them. The peak age group in this study was similar to that found in a Scottish study of sports medicine clinics. ${ }^{19}$ It should be noted, however, that the ABS participation data used for comparison excluded activities such as running, jogging, and walking unless organised by a club or association. As many older people exercise by walking, they may have been excluded from these participation data.

These data also suggest that men are more likely to attend sports medicine clinics for treatment of a sport/recreation injury. However, a similar male excess has been reported for sports injury presentations at hospital emergency departments $(82 \%)^{7}$ and general practitioners $(80 \%) .{ }^{10}$ Given that $52.6 \%$ of men in Australia participate in sport and recreation activities compared with $43.0 \%$ of women, ${ }^{16}$ this finding is consistent with an excess risk of sports injury in men.

Although a large proportion of patients have club/association insurance, many patients do not. The proportion of sports injury patients with hospital health insurance is larger than that of the general population, suggesting that financial considerations play a part in choosing to attend a sports medicine clinic.

A large proportion of patients (41.3\%) referred themselves to the sports medicine clinics, which is lower than the $59.6 \%$ who referred themselves to sports medicine clinics in Scotland during 1993-1995..$^{20}$ In contrast, an earlier Scottish study of a sports injury clinic within a sports centre found that $43.7 \%$ of all cases were referred by sports centre management. ${ }^{19}$ Many patients were also referred to the clinics by friends, showing that referral to sports medicine clinics is from a variety of sources, and patients are not just referred directly from a competitive sport setting. Indeed, although a large proportion of patients were injured during formal sporting competition, $15.0 \%$ were injured during recreation and $10.7 \%$ during self training. This suggests that sustaining an injury during formal competitive sporting activity is not the sole reason for seeking treatment at a sports medicine clinic. Location was the most commonly cited reason for patients choosing to attend one of the participating sports medicine clinics. This reason was also commonly given by patients attending a general practitioner for treatment of a sport/ recreational injury. ${ }^{10}$

The high capture rate associated with the SMIS project database indicates that the data collected are representative of cases presenting to these sports medicine clinics. However, as the patients included in this study were not members of a well defined cohort, it is not possible to assess how representative this sample is of all sports injury cases in the area serviced by the clinics. The comparative data presented here certainly show that patients attending sports medicine clinics are both younger and more likely to be men than both the general population and general sports participants. More extensive studies of additional sports medicine clinics in well defined geographic regions are needed to ascertain fully the extent to which these observations can be generalised to a wider population of patients of sports medicine clinics. Population based studies, including sports medicine attendance, also need to be conducted to enable the calculation of sports injury rates in a population and to put into perspective the number of patients attending sports medicine clinics. Despite these limitations, this study provides valuable information that can be used to help sports medicine clinics market their services more effectively to meet the needs of their potential patients.

In summary, this study provides a profile of typical patients who attend sports medicine clinics for sports injury treatment. They are likely to be 15-30 years old, which largely reflects the sports participation rates in this age group. They come from both professional and non-professional backgrounds and are likely to be students or professionals, reflecting the age group of patients who attend sports medicine clinics and the fact that some patients are required to pay for their own treatment. Sports medicine clinics serve a broad cross section of the community and levels of sports participation. Participants in a variety of sporting/ recreation activities and contexts attend sports medicine clinics for injury treatment. Although the clinics mainly serve the immediate geographic community, the sports speciality and particular expertise of the professionals within a clinic can attract patients from throughout the state.

This study was funded by the National Sports Research Centre of the Australian Sports Commission. C F F was supported by a Public Health Research and Development Committee (of the National Health and Medical Research Council) Research Fellowship. The Sports Medicine Injury Surveillance project was conducted within the five clinics of the Sports Medicine Centres of Victoria group: Croydon Sports Medicine Centre, Malvern Sports Medicine Centre, Peninsula Sports Medicine Centre, Prahran Sports Medicine Centre and Westgate Sports Medicine Centre. The staff and patients of the participating clinics are thanked for their involvement in this project.

1 Egger G. Sports injuries in Australia: causes, cost and prevention. Health Promotion fournal of Australia 1991;1:28-33.

2 Commonwealth Department of Health and Family Services and Australian Institute of Health and Welfare. National Health Priority Areas Report: Injury Prevention and Control 1997. Canberra: Department of Health and Family trol 1997. Canberra: Department of Health and Family Services and Australian Institute of Health

3 Finch C, McGrath A. SportSafe Australia: a national sports safety framework. A report prepared for the Australian Sports Injury Prevention Taskforce. Government report. Canberra: Australian Sports Commission, 1997

4 Commonwealth Department of Human Services and Health. Better Health Outcomes for Australians. National goals targets and strategies for better health outcomes into the next century, Canberra: Australian Government Publishing Services, 1994.

5 Finch C, Valuri G, Ozanne-Smith J. Sport and active recreation injuries in Australia: evidence from emergency

6 Finch C, Cassell E, Stathakis V. The epidemiology of sport and active recreation injury in the Latrobe Valley. Melbourne: Monash University Accident Research Centre, 1999. Report No 151 . 
7 Rowell S, Rees-Jones A. Injuries treated at a sports injury clinic compared with a neighbouring accident and emergency department. Br f Sports Med 1988,22:157-60.

Grimble S, Kendall IG, Allen MJ. An audit of care received by patients injured during sporting activities. Arch Emerg Med 1993;10:203-8.

9 Baquie P, Brukner P. Injuries presenting to an Australian sports medicine centre: a 12 month study. Clin $\mathcal{F}$ Sport Med 1997;7:28-31.

10 Jago D, Finch C. Sporting and recreational injuries in a general practice setting. Aust Fam Physician 1998;27:389-95.

11 Chan KM, Yuan Y, Li Pg CK, et al. Sports causing most injuries in Hong Kong. Br F Sports Med 1993;27:263-7.

2 McClure R. Injury and general practice in Australia. Aust Fam Physician 1995;24:2059-63.

13 Knill-Jones R. Sports injury clinics. $\mathrm{Br}$ f Sports Med 1997;31:95-6.

14 Watkins J, Peabody P. Sports injuries in children and adolescents treated at a sports injury clinic. $\mathcal{F}$ Sports Med Phys Fitness 1996;36:43-8.
15 Australian Bureau of Statistics. Victoria at a glance. Canberra: Australian Bureau of Statistics, 1999. Catalogue
No 1305.5.

16 Australian Bureau of Statistics. Participation in sport and physical activities, 1997-98. Canberra: Australian Bureau of Statistics, 1998. Catalogue No 4177.0.

17 Australian Bureau of Statistics. Labour force Canberra: Australian Bureau of Statistics, 1997. Catalogue No 6202.2

18 Private Health Insurance Administration Council. Quarterly statistics: hospital table membership and coverage and ancillary table membership and coverage. Canberra: Private Health Insurance Administration Council, 1999.

19 Walker AB. A sports injury clinic: a five year experience. $\mathrm{PhD}$ thesis, Glasgow University, 1989.

20 Nielsen A, Knill-Jones R. Usage of sports medicine clinics in Scotland. Final report to the Scottish Sports Council. Glasgow: Department of Public Health, University of Glasgow, 1996.

\section{Take home message}

Sports medicine clinics provide multidisciplinary treatment to a broad spectrum of injured sports participants across a cross section of sporting/recreation activities and levels of participation. Although the clinics mainly serve the immediate geographic community, the sports speciality and particular expertise of a clinic can attract patients from further afield.

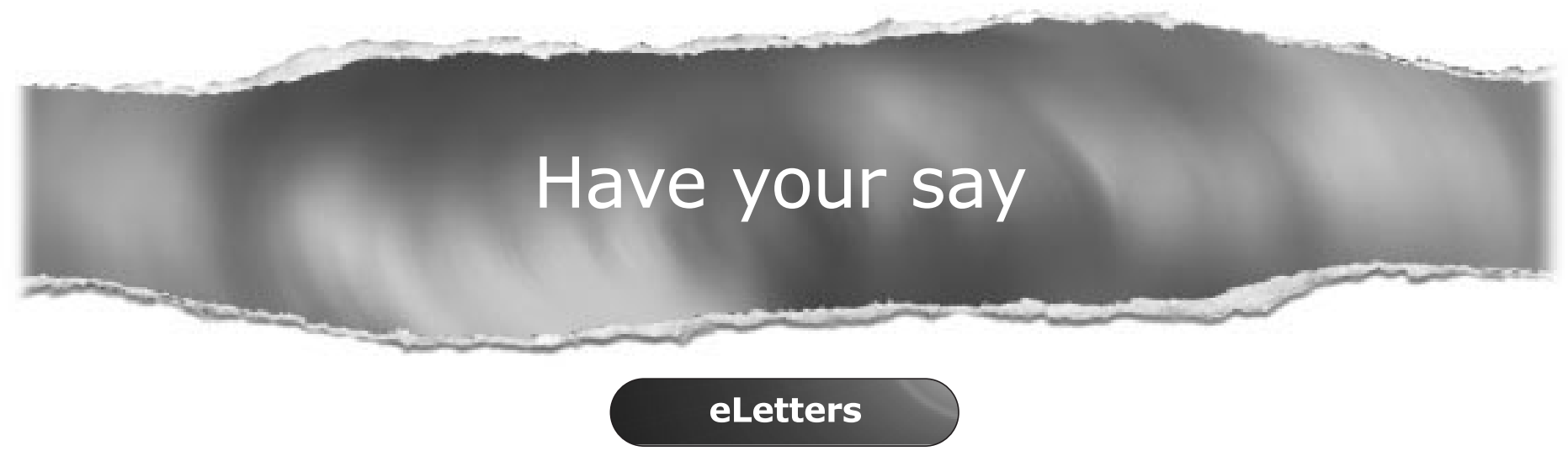

If you wish to comment on any article published in the British Journal of Sports Medicine you can send an eLetter using the eLetters link at the beginning of each article. Your response will be posted on British Journal of Sports Medicine online within a few days of receipt (subject to editorial screening).

www.bjsportmed.com 